\title{
COMPARISON OF THREE COMMERCIAL AUTOMATIC BOOM HEIGHT SYSTEMS FOR AGRICULTURAL SPRAYERS
}

\author{
T. A. Burgers, J. D. Gaard, B. J. Hyronimus
}

\section{HighLIGHTS}

- Three automatic boom height systems were compared: BoomTrac Pro (A), AutoBoom XRT (B), and UC5 Passive Roll (C).

- Boom leveling performance was quantified for three runs on each of three terrains for at least three speeds.

- System B kept the boom height significantly closer to target than Systems A and C.

- System B had significantly less boom height variability than Systems A and C.

ABSTRACT. Automatic boom height systems reduce the variability of agricultural sprayer boom height. Consistent boom height is important for three key reasons: to reduce uneven spray dispersion if the boom is too low, to reduce spray droplet drift if the boom is too high, and to reduce damage to the boom or crop if the boom is too low. No data is available comparing commercial boom height systems. Three leading North American automatic boom height systems were compared: John Deere BoomTrac Pro ${ }^{T M}$ (System A), Raven AutoBoom ${ }^{\circledR}$ XRT (System B), and Norac UC5TM Passive Roll ${ }^{\text {TM }}$ (System C) on a John Deere R4045 (Systems A and B) and RoGator 1100C (Systems B and C). Each system was evaluated with three test runs for at least three speeds over each of a mild, medium, and rough terrain course. Boom heights at the left and right outside sensors were measured with the AutoBoom XRT sensors. The accuracy of the automatic boom height systems was quantified with root mean squared deviation (RMSD), the Herbst-modified Hockley Index, and the fraction of points within 10 and $25 \mathrm{~cm}$ of target $\left(f_{10}\right.$ and $\left.f_{<25}\right)$. With four exceptions out of 216 comparisons, System B significantly outperformed System $A$ on the R4045 and System $C$ on the RoGator for each metric, at each sensor location, at each speed, on each terrain. At $26 \mathrm{~km} / \mathrm{h}$ on medium terrain, the RMSD for Systems A and C was $174 \%$ and $107 \%$ larger than System B, respectively. At $26 \mathrm{~km} / \mathrm{h}$ on medium terrain, the fraction of points within $25 \mathrm{~cm}\left(f_{<25}\right)$ was $56 \%$ and $21 \%$ higher for System B than Systems A and C, respectively. These results indicate System B kept the boom significantly closer to target with significantly less height variability.

Keywords. Automatic control, Boom control, Spray boom, Spray dispersion, Spray drift, Spray height.

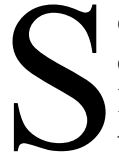
elf-propelled sprayers are commonly used in agriculture to disperse herbicides, pesticides and fertilizers. They generally consist of a centrally-located tractor and two boom wings for a total sprayer width up to $48 \mathrm{~m}$ (158 ft). The booms have nozzles to distribute the chemicals or fertilizer. Ideally, each nozzle will maintain a constant distance to the target spray area, but practically the

\footnotetext{
(c) (i) $(-)$ The authors have paid for open access for this article. This work is licensed under a Creative Commons AttributionNonCommercial-NoDerivatives 4.0 International License https://creative commons.org/licenses/by-nc-nd/4.0/

Submitted for review on 1 October 2020 as manuscript number MS 14346; approved for publication as a Research Article by the Machinery Systems Community of ASABE on 3 February 2021.

The authors are Travis A. Burgers, Staff Design Engineer, Applied Technology Division, Raven Industries, Sioux Falls, South Dakota, and Adjunct Assistant Professor, Department of Mechanical Engineering, South Dakota State University, Brookings, South Dakota; John D. Gaard, Senior Test Engineer, and Brian J. Hyronimus, Engineering Manager, Applied Technology Division, Raven Industries, Sioux Falls, South Dakota. Corresponding author: Travis A. Burgers, 205 E. 6th Street, Sioux Falls, SD 57104; phone: 605-575-0569; email: travis.burgers@ravenind.com.
}

height of the boom relative to the target area changes due to terrain variations, differences in crop height, and the roll angle of the sprayer (Herbst et al., 2018). Sprayers roll due to soil unevenness (Speelman and Jansen, 1974; Tahmasebi et al., 2013), and the rigid body motion of the sprayer causes more severe boom height variability than terrain or crop height variability (Ramon and De Baerdemaeker, 1997). Various methods have been used to reduce boom height variation (Tahmasebi et al., 2013). In the current generation of automatic boom height control systems, ultrasonic sensors are primarily used to measure distance from the target area (Herbst et al., 2018), although Raven Industries' AutoBoom XRT (Sioux Falls, S.D.) uses radar sensors. The sensors' measurements provide feedback for a control system that actively adjusts the boom to minimize deviation from an operator-specified target height.

Automatic boom height systems reduce the variability in boom height which is important for three key reasons. First, if the boom height is lower than the target, uneven spray dispersion can occur (Speelman and Jansen, 1974; Ramon and De Baerdemaeker, 1997). Adjacent nozzles typically 
overlap coverage (Lardoux et al., 2007; Butts et al., 2019). A lower boom will prevent proper overlap (Lardoux et al., 2007) or even cause a complete lack of application (Clijmans et al., 2000). These cases are problematic because weeds can develop resistance to herbicides when they receive sublethal doses (Neve and Powles, 2005; Busi and Powles, 2011; Tehranchian et al., 2017). In the area directly under the nozzle, severe overapplication (up to six times the target rate) could occur (Clijmans et al., 2000), which results in wasted product and is environmentally harmful. Second, as the height of the boom increases, droplet drift increases (Holterman et al., 1997; Nuyttens et al., 2007; Baetens et al., 2009). For example, when boom height increases from 40 to $80 \mathrm{~cm}$, the drift percentage triples (Nordby and Skuterud, 1975). Drift is known to be problematic for dicamba and 2,4D (Egan et al., 2014; Werle et al., 2018), two chemicals that have increased usage due to the development of transgenic, chemical-resistant soybeans and cotton. With as little as $0.5 \%$ of their labeled rates, these chemicals damage and decrease the yield of non-resistant soybeans and cotton (Everitt and Keeling, 2009; Griffin et al., 2013; Foster et al., 2018). The number of complaints from farmers without dicambaresistant soybeans and cotton rapidly have increased due to damage on their crops (Foster et al., 2018; Scoll, 2019). Third, if the boom height is too low damage to the boom (Griffith et al., 2012) or to the crop could occur.

Automatic boom height systems provide the additional benefit of allowing the sprayer operator to focus on other parts of the spraying task than exclusively watching the boom, especially when spraying at high ground speed (Herbst et al., 2018). While increased sprayer ground speed improves sprayer throughput, increased sprayer speed also increases the vertical motion of the boom (Langenakens et al., 1999) and vibration (Langenakens et al., 1995). In North America sprayer commercial applicators commonly drive $20-29 \mathrm{~km} / \mathrm{h}(12-18 \mathrm{mi} / \mathrm{h}$ ) (Meyer et al., 2016; Carroll, 2017; Womac et al., 2017) and in the authors' experience some drive even faster. In Europe, speeds are typically slower, e.g., in Germany the maximum recommended travel speed is $8 \mathrm{~km} / \mathrm{h}(5 \mathrm{mi} / \mathrm{h})$ (Herbst et al., 2018). Increased sprayer speed also reduces the reaction time for an automatic boom height control system to adjust the boom back to the target height (Paraforos et al., 2019).

Automatic boom height system comparison is difficult because results are dependent on the track and speed (Griffith et al., 2012). A variable called the Hockley Index was developed to quantify spray height, and thus automatic boom height performance (Griffith et al., 2012). Herbst et al. (2018) used root mean square deviation and proposed two additional parameters: $\mathrm{f}_{10}$, and a modified version of the Hockley Index, which by its definition is always less than or equal to the Hockley Index. These measures can only be directly compared when testing is done on the same track at the same speed with the same sensor locations along the boom. To the authors' knowledge there are no published comparisons of the performance of automatic boom height systems, so the hypothesis of this work is that the comparison measures described previously can be used to differentiate the performance of three commercial automatic boom height products.

\section{MATERIALS AND MeTHOdS}

\section{Automatic Boom Height Systems ANd SPRAYERS}

Three automatic boom height systems were evaluated:

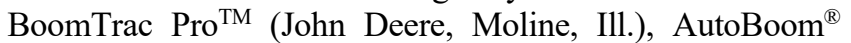
XRT (Raven Industries, Sioux Falls, S.D.) and Norac UC5 ${ }^{\mathrm{TM}}$ Passive Roll ${ }^{\mathrm{TM}}$ (Topcon Agriculture Canada Inc., Saskatoon, SK). System information is described in table 1. Each system had five boom height sensors, but center rack (also known as center boom or center section) height control was turned off. Each automatic boom height system used the factory-installed sprayer hydraulic system to adjust the height of the boom.

A John Deere R4045 sprayer with a 36.6-m (120-ft) boom was used to compare the factory-installed System A with System B. The sprayer had Firestone IF 380/105R50 tires (Nashville, Tenn.) at $410 \mathrm{kPa}$ (60 psi) and $1980 \mathrm{~L}$ (524 gal) of water in the tank.

Table 1. Automatic boom height systems information.

\begin{tabular}{|c|c|c|c|c|c|c|c|c|}
\hline System & $\begin{array}{l}\text { System } \\
\text { Name }\end{array}$ & Sprayer & $\begin{array}{c}\text { Software/ } \\
\text { Firmware }^{[a]}\end{array}$ & $\begin{array}{l}\text { Software } \\
\text { Mode }\end{array}$ & $\begin{array}{c}\text { Response/ } \\
\text { Sensitivity }{ }^{[\mathrm{b}]}\end{array}$ & Installation Notes & System Sensors ${ }^{[c]}$ & $\begin{array}{l}\text { MSRP } \\
\text { (US\$) }\end{array}$ \\
\hline Sys A & $\begin{array}{c}\text { John Deere } \\
\text { BoomTrac } \\
\text { Pro } \\
\end{array}$ & R4045 & $\begin{array}{c}01.45 . \\
1905091618\end{array}$ & $\begin{array}{l}\text { "Flat"/ } \\
\text { "Hilly"[d]; } \\
\text { "Ground" }\end{array}$ & $\begin{array}{c}3 \\
\text { (1-5 scale) }\end{array}$ & $\begin{array}{l}\text { Factory-installed } \\
\text { at John Deere }\end{array}$ & $\begin{array}{l}\text { Center frame tilt sensor: } \\
\text { Factory-installed R4045 sensor, } \\
\text { Chassis sensor: none } \\
\end{array}$ & 14,600 \\
\hline Sys B & $\begin{array}{l}\text { Raven } \\
\text { AutoBoom } \\
\text { XRT }\end{array}$ & R4045 & 1.0 .25 .3 & "Ground" & $\begin{array}{c}50 \\
(1-100 \text { scale })\end{array}$ & $\begin{array}{c}\text { Installed by experienced } \\
\text { Raven technicians, } \\
\text { no optional dampers } \\
\text { were used }^{[\mathrm{f}]} \\
\end{array}$ & $\begin{array}{c}\text { Center frame tilt sensor: } \\
\text { Factory-installed R4045 sensor, } \\
\text { Chassis sensor: Raven-installed sys- } \\
\text { tem inertial measurement sensor }\end{array}$ & 14,600 \\
\hline Sys B & $\begin{array}{l}\text { Raven } \\
\text { AutoBoom } \\
\text { XRT }\end{array}$ & RoGator & 1.0 .25 .3 & "Ground" & $\begin{array}{c}80 \\
(1-100 \text { scale })\end{array}$ & $\begin{array}{c}\text { Installed by experienced } \\
\text { Raven technicians, } \\
\text { optional dampers } \\
\text { were used } \\
\end{array}$ & $\begin{array}{l}\text { Center frame tilt sensor: Raven- } \\
\text { installed center rack tilt sensor, } \\
\text { Chassis sensor: Raven-installed } \\
\text { system inertial measurement sensor }\end{array}$ & 14,600 \\
\hline Sys C & $\begin{array}{l}\text { Norac } \\
\text { UC5 } \\
\text { Passive } \\
\text { Roll } \\
\end{array}$ & RoGator & 6.2 .0 .0 & "Soil" & $\begin{array}{c}8 \\
(1-10 \text { scale) }\end{array}$ & $\begin{array}{c}\text { Factory-installed } \\
\text { at AGCO }\end{array}$ & $\begin{array}{l}\text { Center frame tilt sensor: Factory- } \\
\text { installed Norac system roll sensor, } \\
\text { Chassis sensor: Factory-installed } \\
\text { Norac system roll sensor }\end{array}$ & 13,800 \\
\hline \multirow{3}{*}{\multicolumn{9}{|c|}{$\begin{array}{l}\text { [a] Controller software for BoomTrac Pro, Software for AutoBoom XRT, Firmware for Norac UC5 Passive Roll. } \\
\text { [b] Raise/lower response for BoomTrac Pro, Sensitivity for AutoBoom XRT and Norac UC5 Passive Roll. } \\
\text { [c] All systems used the factory-installed left and right wing tilt sensors from their respective sprayers. All systems used their own boom height sensors. } \\
\text { [d] "Flat" mode on straightawav "Hilly" mode on terraces }\end{array}$}} \\
\hline & & & & & & & & \\
\hline & & & & & & & & \\
\hline [e] The & de on str & $\begin{array}{l}\text { ghtaway, } \\
\text { ar to be ei }\end{array}$ & $\begin{array}{l}\text { Hilly mo } \\
\text { ther an iner }\end{array}$ & terraces. & & & & \\
\hline [f] Op & & & & & & ol1 & & \\
\hline
\end{tabular}


An AGCO RoGator 1100C (Duluth, Ga.) with a 36.6-m (120-ft) boom was used to compare the factory-installed System C with System B. The sprayer had Michelin Spraybib VF 380/90 R46 tires (Greenville, S.C.) at $400 \mathrm{kPa}$ (58 psi) and $2030 \mathrm{~L}$ (537 gal) of water in the tank.

Sprayer manufacturers use different boom suspension designs to dampen sprayer roll and the forces applied to raise/lower the wings (Miles, 2018). Thus, the response/sensitivity of each boom height system is dependent on the sprayer. To eliminate the contribution of the boom suspension on boom leveling in this comparison, two automatic boom height systems were evaluated on each sprayer.

On the R4045, the System A and B outer sensors were 15.0 and $15.8 \mathrm{~m}$ from the wing connection to the center frame, respectively. On the RoGator, the System B and C outer sensors 14.6 and $15.0 \mathrm{~m}$ from the wing connection to the center frame, respectively. For all systems the target boom height was $101 \mathrm{~cm}$ (40 in.). Tip manufacturers recommend a boom height of 50 and $75 \mathrm{~cm}$ (20 and $30 \mathrm{in}$.) for $110^{\circ}$ and $80^{\circ}$ tips, respectively (Forney et al., 2017), but the height was increased in this study to reduce the risk of boom damage from ground impact.

\section{TraCkS}

The sprayers were driven on two firm sod tracks. The first track was a straightaway. The straightaway course had a generally mild terrain; it crossed a minor waterway about $300 \mathrm{~m}$ from the south end of the course and a larger waterway about $110 \mathrm{~m}$ from the south end of the course. The initial pass was north to south and the return pass was on the same track from south to north. The measured course was about $610 \mathrm{~m}$ long. A waterway course was defined as a subset of this straightaway course to evaluate a different (medium) terrain type, as was suggested by Griffith et al. (2012). It consisted of the $50 \mathrm{~m}$ before and after the larger waterway [see Supplemental fig. S1 (Burgers et al., 2021b)] and included the initial and return passes. The range of elevation was $12 \mathrm{~m}$ over the straightaway track.

The second track was generally rough terrain over a series of four terraces on a flat segment and a hill segment. The initial pass was approximately northwest and the return pass was southeast at a spacing of one boom width $(36.6 \mathrm{~m})$ to the southwest from the first pass. The initial pass of the track was approximately flat (other than the terrace) for about $50 \mathrm{~m}$, then descended $8 \mathrm{~m}$ over the last $100 \mathrm{~m}$. The return pass ascended $8 \mathrm{~m}$ over $100 \mathrm{~m}$, then was approximately flat (other than the terrace) for the remaining $75 \mathrm{~m}$. The terraces were oriented approximately north-south and were traversed at an angle of about $30^{\circ}$ [see Supplemental fig. S1 (Burgers et al., 2021b)]. Testing on the RoGator was offset one tire width to the east on the straightaway and northeast on the terraces relative to testing performed on the R 4045 .

Tracks were programmed in each sprayer's guidance system and autosteering was engaged during test runs. The straightaway was run at 13,19 , and $26 \mathrm{~km} / \mathrm{h}(8,12$, and $16 \mathrm{mi} / \mathrm{h})$. The terraces were run at 10,13 , and $16 \mathrm{~km} / \mathrm{h}(6,8$, and $10 \mathrm{mi} / \mathrm{h})$. On the terrace track, System B was also run at $19 \mathrm{~km} / \mathrm{h}(12 \mathrm{mi} / \mathrm{h})$. The other systems were not run at this speed because of concern over potential boom damage. Speed control was activated for each test run.
For each sprayer, the test run order was (1) System A (R4045)/System C (RoGator), (2) System B, (3) System B, (4) System A/System C, (5) System A/System C, (6) System B. On the RoGator, System B and System C use different spring/damper systems. To switch between them, the other product's spring/damper was removed and the tested product's spring/damper was installed. On the R4045 there were no differing spring/damper components between System A and System B so no hardware was changed between runs. The boom wings were raised and lowered three times after switching systems or after an hour of inactivity to warm the hydraulic oil before tests were conducted.

\section{Data Analysis and Performance Metrics}

Time, sprayer speed, GPS coordinates (from a Raven $\mathrm{RS1}^{\mathrm{TM}}$, Raven Industries), chassis roll angle and boom heights (measured via the sensors AutoBoom XRT system) were logged via the CAN network. Both speed and GPS coordinates were recorded at $10 \mathrm{~Hz}$; chassis roll angle and boom heights were recorded at $20 \mathrm{~Hz}$. The CAN messages were parsed from the logs to read the measurement values. Data was imported and processed in Matlab R2018b (MathWorks, Natick, Mass.). The Matlab data (Burgers and Gaard, 2021) and scripts (Burgers, 2021) are provided as supplemental materials.

The distance the sprayer moved in each time step was calculated as the sprayer speed times the time step. Sprayer logged distance for each time point was calculated as the cumulative distance to that time. Since the sprayer start location and headlands (turnaround) distances were not the same for every run, an aligned distance was calculated. To do this, the latitude values were aligned and then the distance was slightly adjusted for each pass of each track so that the chassis roll angle and speed profiles aligned. The aligned distance includes a slight artificial offset to indicate the transition between the first and second passes of the test run because headlands distances were not the same for each run. The use of aligned distance ensured that the evaluation region was repeatable over the same physical stretch of track for each test run (fig. 1).

The straightaway and terraces courses' evaluation start and stop locations for each pass were determined by identifying a distance where the sprayer speed and chassis roll angle were consistent for all test runs over the course. These locations were $80,720,900$, and $1480 \mathrm{~m}$ for the straightaway and $21,160,250$, and $430 \mathrm{~m}$ for the terraces. The waterway course was a subset of the straightaway course and was defined to be the $50 \mathrm{~m}$ before and after the waterway (602 and $1012 \mathrm{~m}$ on first and second pass, respectively), as determined by the sharp change in chassis roll angle (see fig. 1).

Boom heights at the left and right outside sensors were compared to the target height for the defined evaluation region of each test run. Boom height root mean square deviation (RMSD) was calculated from equation 1. This is the same as "Standard Deviation" Herbst et al. (2018) presented, except they used $\mathrm{N}-1$ in the denominator, but with large $\mathrm{N}$ these values are effectively the same.

$$
R M S D=\sqrt{\frac{\sum_{i=1}^{N}\left(h_{i}-h_{\text {target }}\right)^{2}}{N}}
$$


(a)

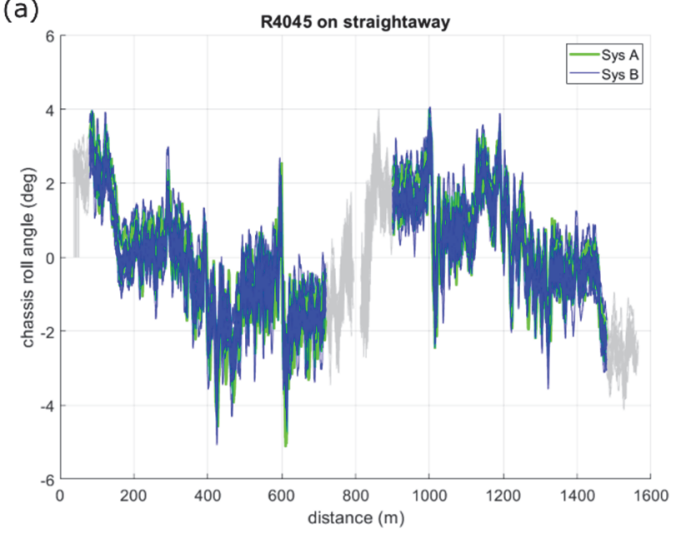

(c)

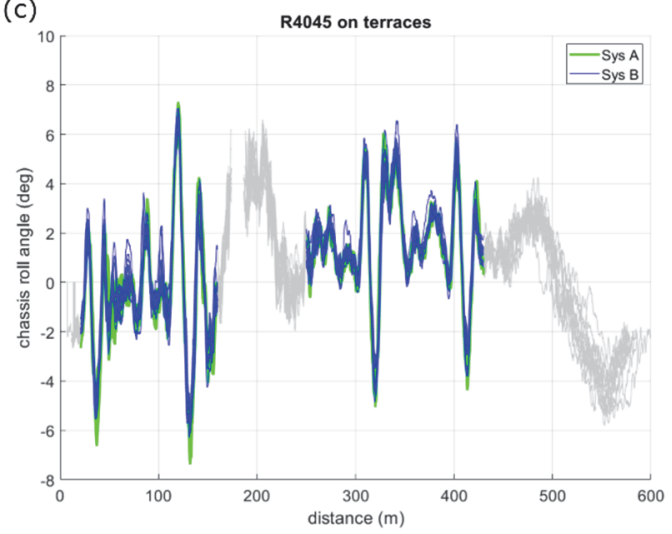

(e)

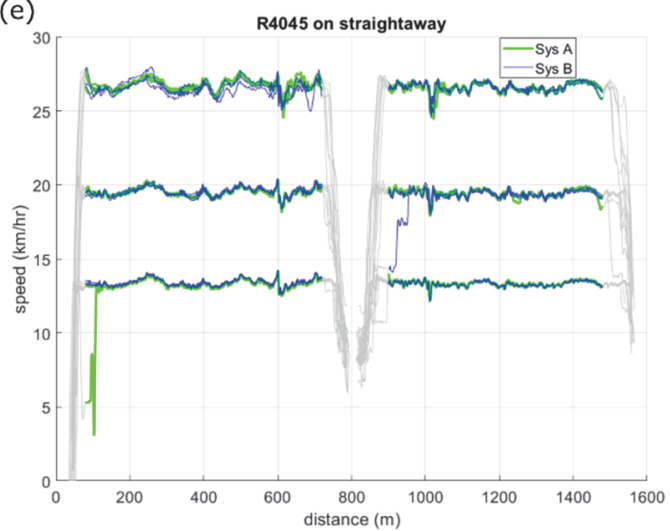

(g)

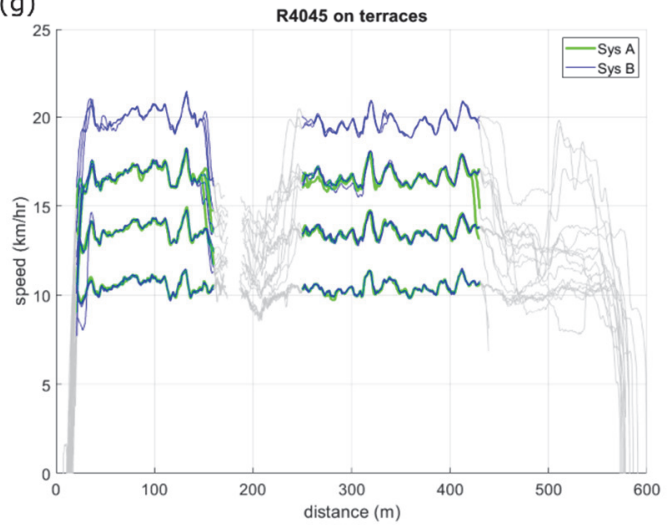

(b)
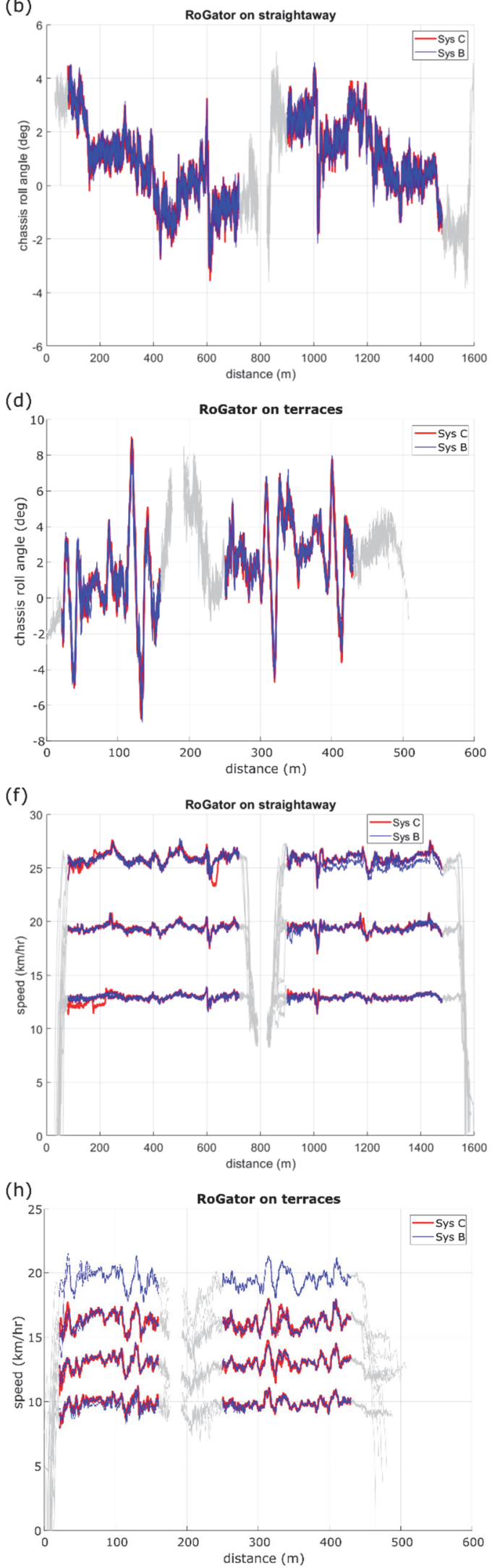

Figure 1. Sprayer chassis roll angle and speed on the straightaway and terraces. Panels (a)-(d) are chassis roll angle; (e)-(h) are speed. Panels (a), (c), (e), and (g) are on the R4045; (b), (d), (f), and (h) are on the RoGator. Panels (a), (b), (e), and (f) are on the straightaway; (c), (d), (g), and (h) are on the terraces. Colored lines indicate the evaluation region for each system and gray lines indicate measurements outside the evaluation region. System $A$ and $C$ lines are thicker than System B lines and were plotted below System B lines. Panels (a), (b), (e), and (f) have 18 runs plotted; (c), (d), (g), and (h) have 21 runs plotted. The run-to-run alignment of chassis roll angle and speed for each sprayer on each course shows the course repeatability among and between systems. 
where

$h_{i}=$ boom height for the $i$ th measurement in the test run, $h_{\text {target }}=$ target boom height, and

$N=$ number of measurements in the test run.

The Herbst-modified Hockley Index (HHI) was calculated from Supplemental equation S1 (Herbst et al., 2018; Burgers et al., 2021b). Boom height $f_{10}$ was calculated as the fraction of measurements with a deviation less than $10 \mathrm{~cm}$ (3.9 in.) from the target height, and $\mathrm{f}_{<25}$ was calculated as the fraction of measurements with a deviation less than $25 \mathrm{~cm}$ ( 0.98 in.), i.e., $f_{10}+f_{25}$ terms in the HHI calculation [see Supplemental Methods (Burgers et al., 2021b)].

Average system differences were calculated for run-level RMSD, HHI, $\mathrm{f}_{10}$ and $\mathrm{f}_{<25}$ performance metrics. Supplemental equation S2 was used to calculate average HHI difference (Burgers et al., 2021b); equation 2 was used to calculate average differences for RMSD, $\mathrm{f}_{10}$ and $\mathrm{f}_{<25}$.

$$
\begin{aligned}
& \text { Average Difference }(\%)= \\
& \frac{\text { Larger average metric }}{\text { Smaller average metric }}-100 \%
\end{aligned}
$$

Boom height data was pooled from both outside sensors from all three runs at the maximum common speed on each course (i.e., $26 \mathrm{~km} / \mathrm{h}$ on the straightaway and waterway and
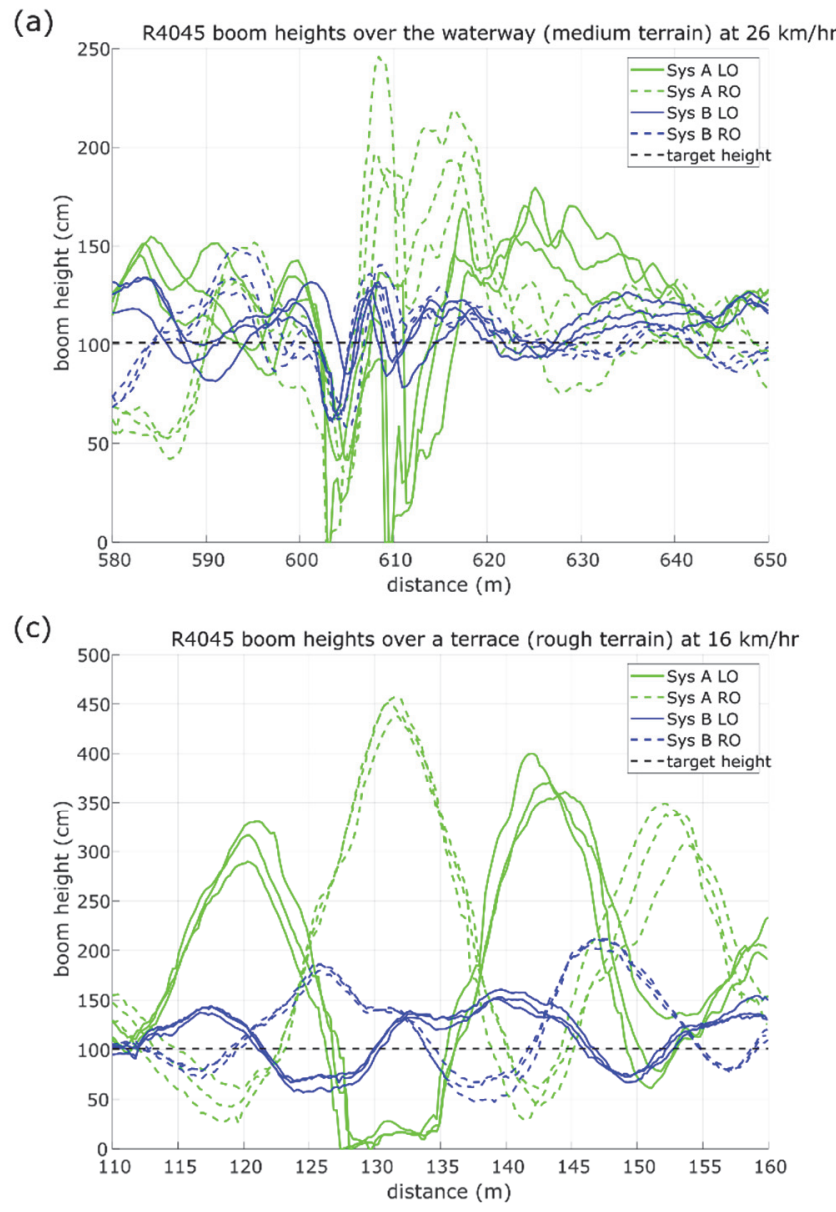

$16 \mathrm{~km} / \mathrm{h}$ on the terraces). Histograms with $5 \mathrm{~cm}$ bins were plotted in Minitab 18 (Minitab, LLC, State College, Pa.) for these combined data sets.

Statistical comparisons were made between systems for each run-level performance metric on each sprayer (i.e., a sample size of the three replicates, or six from the pooled left and right sensors, for each system for all statistical tests). For each of the four metrics (RMSD, HHI, $\mathrm{f}_{10}$ and $\mathrm{f}_{<25}$ ) on each sprayer there were 27 common sensor/speed/terrain comparisons [3 sensor locations (left, right, and pooled left and right $) \times 3$ speeds $\times 3$ terrains]. Welch's unequal variances $t-$ test was performed in Excel (Excel for Office 365, Microsoft, Redmond, Wash.) with $\mathrm{p}<0.05$ considered significant.

\section{RESULTS}

Figure 2 shows a sample of the boom height data from three runs over the waterway at $26 \mathrm{~km} / \mathrm{h}$ and over a terrace at $16 \mathrm{~km} / \mathrm{h}$. System B drastically reduced boom height minimum and maximum extremes compared to Systems A and C. For example, on the terrace the maximum left and right outside boom heights for System B were approximately 160 and $210 \mathrm{~cm}$ on the R4045 and 170 and $220 \mathrm{~cm}$ on the RoGator, respectively. For Systems A and C these were 400 and
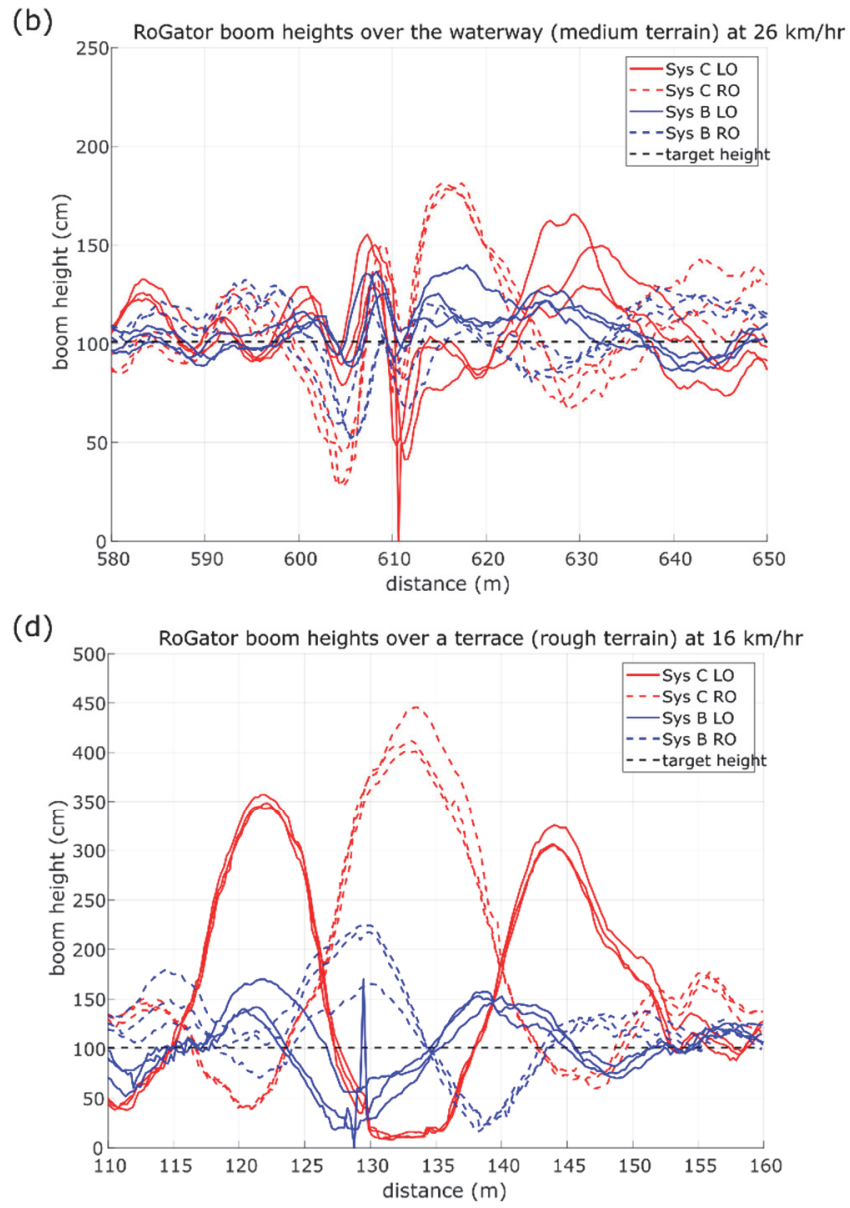

Figure 2. Boom heights at left outside (solid) and right outside (dashed) sensors from each of the three runs (a) R4045 over the waterway (medium terrain) at $26 \mathrm{~km} / \mathrm{h}$, (b) RoGator over the waterway (medium terrain) at $26 \mathrm{~km} / \mathrm{h}$, (c) R4045 over a terrace (rough terrain) at $16 \mathrm{~km} / \mathrm{h}$, and (d) RoGator over a terrace (rough terrain) at $16 \mathrm{~km} / \mathrm{h}$. System B maintained a boom height closer to the target height on each sprayer on each course. 

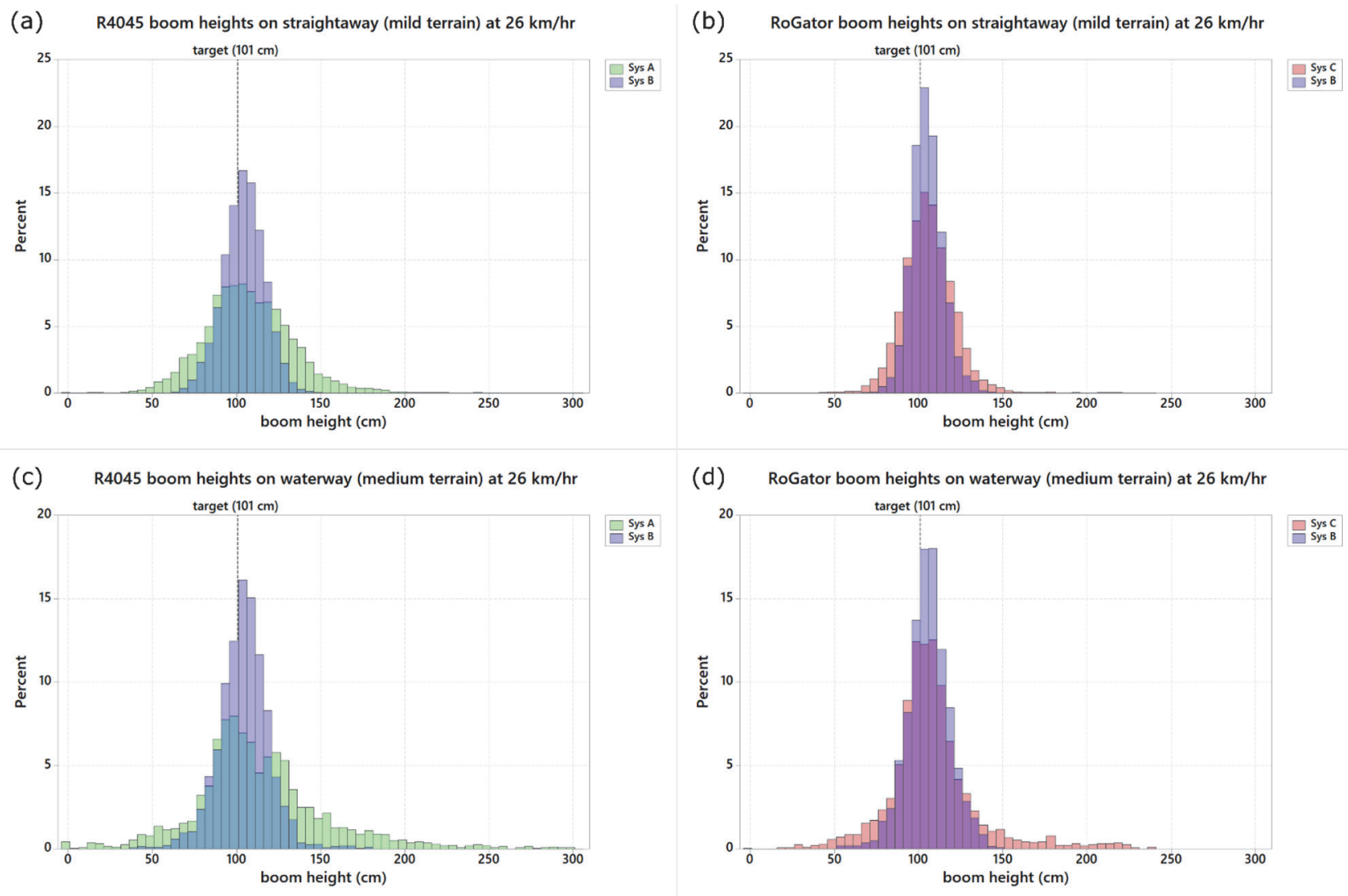

(d) RoGator boom heights on waterway (medium terrain) at $26 \mathrm{~km} / \mathrm{hr}$
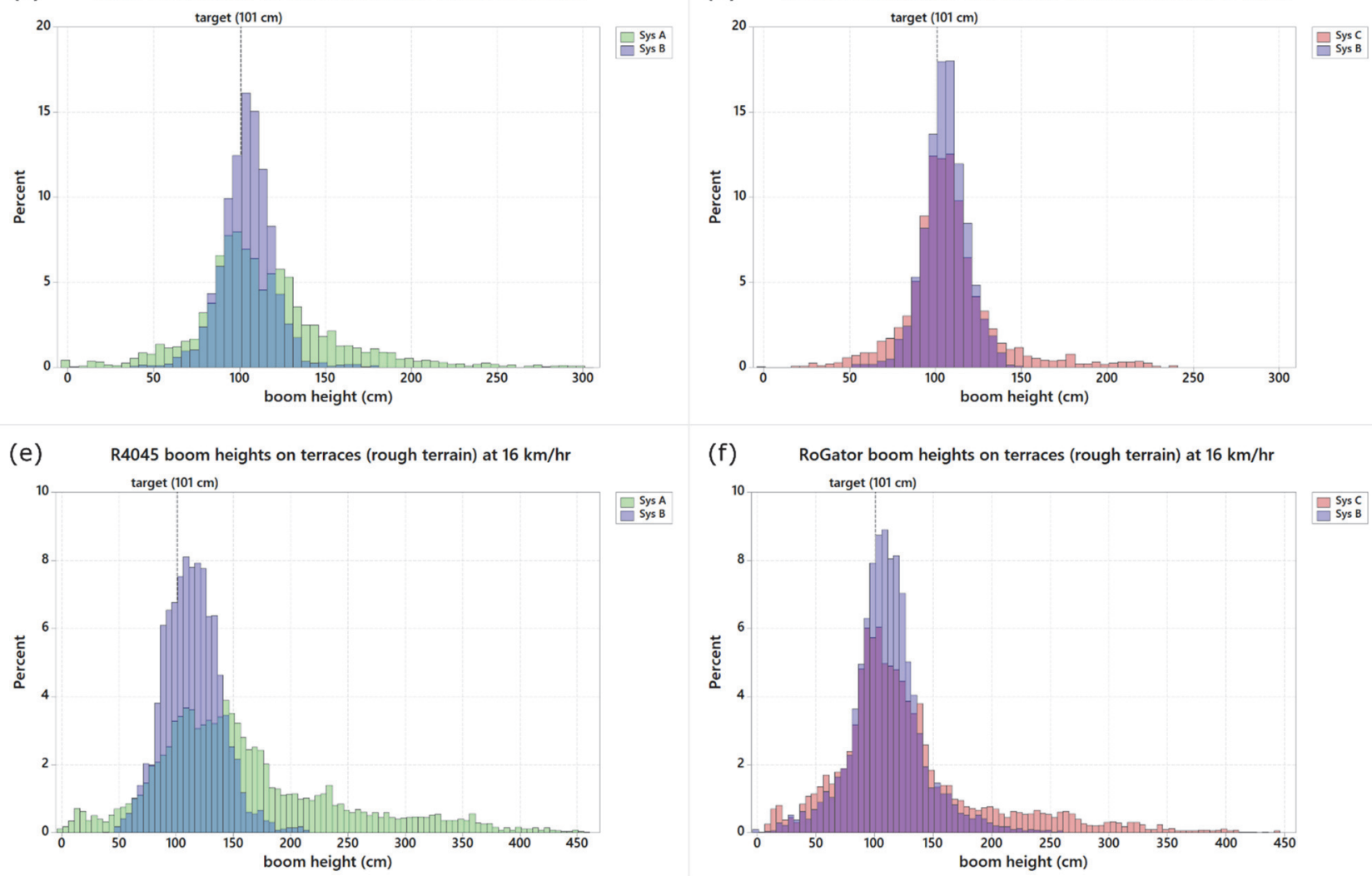

Figure 3. Histograms of combined left outside and right outside boom heights for all three runs at the maximum common speed tested for each course. Panels (a), (c), and (e) are on the R4045; (b), (d), and (f) are on the RoGator; (a) and (b) are on the straightaway (mild terrain); (c) and (d) are on the waterway (medium terrain); and (e) and (f) are on the terraces (rough terrain). The data bins are $5 \mathrm{~cm}$. System B had a distribution closer to the target boom height than System $A$ and System $C$ for all courses.

$450 \mathrm{~cm}$ and 360 and $450 \mathrm{~cm}$, respectively. Figure 3 shows histogram data from the maximum common speed on each course. The distribution of boom heights was tighter for System B than for Systems A and C on each terrain.

Summary run-level results are provided as supplemental materials (Burgers et al., 2021a). RMSD with respect to speed is shown in figure 4 and average RMSD difference is shown in table 2. Systems A and C had a significantly larger RMSD than System B for each sensor location, at each speed, on each terrain (27 comparisons each). Compared to System B, System A had an average RMSD increase of $154 \%, 269 \%$, and $183 \%$ on the mild, medium, and rough terrains, respectively. At the maximum common speed, the average RMSD increase between the two sensors was $120 \%$,
$174 \%$, and $256 \%$ on the three terrains, respectively (table 2 ). Compared to System B, System C had an average RMSD increase of $60 \%, 89 \%$, and $153 \%$ on the mild, medium, and rough terrains, respectively. At the maximum common speed, the average RMSD increase between the two sensors was $70 \%, 107 \%$, and $122 \%$ on the three terrains, respectively (table 2).

Average HHI and HHI difference are shown in Supplemental table S1 (Burgers et al., 2021b). System B had a significantly larger HHI than Systems A and C for each sensor location, at each speed, on each terrain (27 comparisons each).

Figures 5 and 6 show boom height $f_{10}$ and $f_{<25}$ with respect to speed. The average $f_{10}$ and $f_{<25}$ difference is shown in 


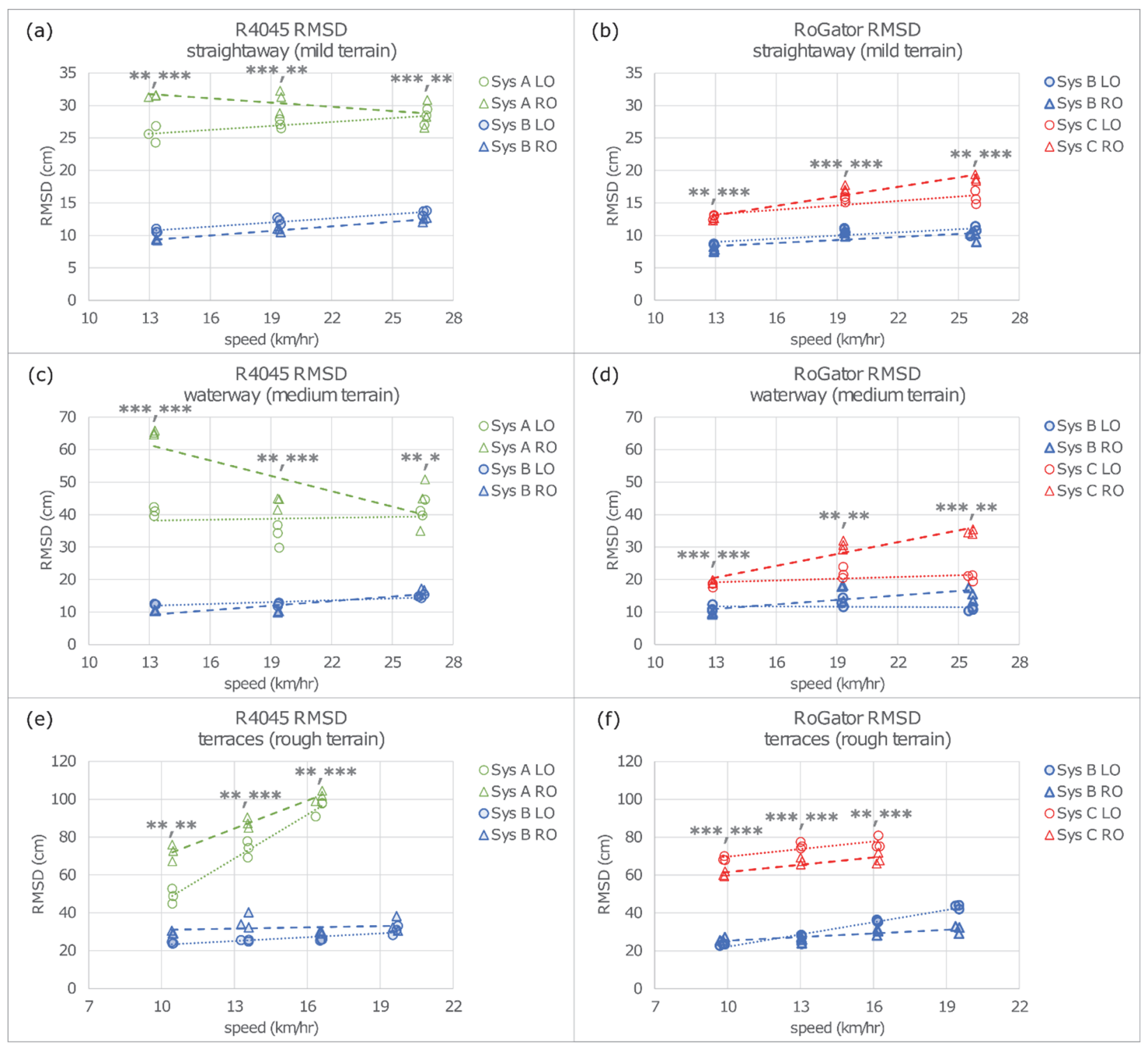

Figure 4. Boom height RMSD of left outside (LO) and right outside (RO) sensors. Panels (a), (c), and (e) are on the R4045; (b), (d), and (f) are on the RoGator; (a) and (b) are on the straightaway (mild terrain); (c) and (d) are on the waterway (medium terrain); and (e) and (f) are on the terraces (rough terrain). Significance is indicated for each speed by (left outside, right outside) where * $p<0.05, * * p<0.01$ and $* * * p<0.001$. Systems A and C had a significantly larger RMSD than System $B$ for each sensor location at each speed on each course.

table 3. With three exceptions, System B had a significantly larger $\mathrm{f}_{10}$ than Systems A and $\mathrm{C}$ for each sensor location, at each speed, on each terrain (27 comparisons each). For these three exceptions the sensor/speed/terrain $\mathrm{f}_{10}$ was larger for System B than System C, but the difference was not statistically significant. With one exception, System B had a significantly larger $\mathrm{f}_{<25}$ than Systems A and $\mathrm{C}$ for each sensor location, at each speed, on each terrain (27 comparisons each). For this exception the sensor/speed/terrain $\mathrm{f}_{<25}$ was larger for System B than System C, but the difference was not statistically significant. Compared to System A, System B had an average $\mathrm{f}_{10}$ increase of $76 \%, 102 \%$, and $104 \%$ on the mild, medium, and rough terrains, respectively. For $f_{<25}$ the average increase was $30 \%, 52 \%$, and $90 \%$ on the three terrains, respectively. At the maximum common speed, the average $f_{10}$ increase between the two sensors was $82 \%$, $85 \%$, and $121 \%$ on the three terrains, respectively. At the maximum common speed, average $\mathrm{f}_{<25}$ increase was $39 \%$,
$56 \%$, and $121 \%$ on the three terrains, respectively (table 3 ). Compared to System C, System B had an average $\mathrm{f}_{10}$ increase of $30 \%, 34 \%$, and $64 \%$ on the mild, medium, and rough terrains, respectively. For $\mathrm{f}_{<25}$ the average increase was $7 \%, 18 \%$, and $45 \%$ on the three terrains, respectively. At the maximum common speed, the average $f_{10}$ increase between the two sensors was $36 \%, 26 \%$, and $43 \%$ on the three terrains, respectively. At the maximum common speed, average $\mathrm{f}_{<25}$ increase was $8 \%, 21 \%$, and $39 \%$ on the three terrains, respectively (table 3 ).

\section{DisCUSSION}

\section{BOOM LEVELING COMPARISON AND IMPLICATIONS}

Various work has been done to improve and evaluate sprayer boom height (Speelman and Jansen, 1974; Langenakens et al., 1995, 1999; Ramon and De Baerdemaeker, 1997; Lardoux et al., 2007; Griffith et al., 
Table 2. Average boom height RMSD difference (\%) for Systems $A$ and $C$ relative to System $B .^{[a]}$

\begin{tabular}{|c|c|c|c|c|c|c|}
\hline \multirow[b]{3}{*}{ Course } & \multirow{3}{*}{$\begin{array}{c}\text { System } \\
\text { (Sprayer) }\end{array}$} & \multirow[b]{3}{*}{ Sensor } & \multicolumn{4}{|c|}{ Average RMSD Difference $(\%)^{[b]}$} \\
\hline & & & \multicolumn{3}{|c|}{ Speed $(\mathrm{km} / \mathrm{h})$} & \multirow[b]{2}{*}{ Avg. ${ }^{[c]}$} \\
\hline & & & 13 & 19 & 26 & \\
\hline \multirow{6}{*}{$\begin{array}{l}\text { Straight- } \\
\text { away } \\
\text { (mild } \\
\text { terrain) }\end{array}$} & \multirow{3}{*}{$\begin{array}{c}\text { System A } \\
\text { (R4045) }\end{array}$} & LO & $139 * *$ & $121 * * *$ & $110 * * *$ & 123 \\
\hline & & RO & $237 * * *$ & $184 * *$ & $130 * *$ & 184 \\
\hline & & pooled & $188 * * *$ & $153 * * *$ & $120 * * *$ & 154 \\
\hline & \multirow{3}{*}{$\begin{array}{l}\text { System C } \\
\text { (RoGator) }\end{array}$} & $\mathrm{LO}$ & $49 * *$ & $43 * * *$ & $48 * *$ & 47 \\
\hline & & RO & $60 * * *$ & $67 * * *$ & $91 * * *$ & 73 \\
\hline & & pooled & $55 * * *$ & $55 * * *$ & $70 * * *$ & 60 \\
\hline \multirow{6}{*}{$\begin{array}{c}\text { Water- } \\
\text { way } \\
\text { (medium } \\
\text { terrain) }\end{array}$} & \multirow{3}{*}{$\begin{array}{c}\text { System A } \\
\text { (R4045) }\end{array}$} & $\mathrm{LO}$ & $231 * * *$ & $172 * *$ & $182 * *$ & 195 \\
\hline & & RO & $530 * * *$ & $332 * * *$ & $166^{*}$ & 343 \\
\hline & & pooled & $380 * * *$ & $252 * * *$ & $174 * * *$ & 269 \\
\hline & \multirow{3}{*}{$\begin{array}{l}\text { System C } \\
\text { (RoGator) }\end{array}$} & LO & $64 * * *$ & $71 * *$ & $90 * * *$ & 75 \\
\hline & & RO & $100 * * *$ & $86^{* *}$ & $124 * *$ & 103 \\
\hline & & pooled & $82 * * *$ & $78 * *$ & $107 * *$ & 89 \\
\hline \multirow[b]{2}{*}{ Course } & \multirow{2}{*}{$\begin{array}{c}\text { System } \\
\text { (Sprayer) }\end{array}$} & & \multicolumn{3}{|c|}{ Speed $(\mathrm{km} / \mathrm{h})$} & \\
\hline & & Sensor & 10 & 13 & 16 & Avg. ${ }^{[c]}$ \\
\hline \multirow{6}{*}{$\begin{array}{c}\text { Terraces } \\
\text { (rough } \\
\text { terrain) }\end{array}$} & \multirow{3}{*}{$\begin{array}{c}\text { System A } \\
\text { (R4045) }\end{array}$} & $\mathrm{LO}$ & $103 * *$ & $191 * *$ & $271 * *$ & 188 \\
\hline & & RO & $144 * *$ & $147 * * *$ & $242 * * *$ & 177 \\
\hline & & pooled & $123 * *$ & $169 * * *$ & $256 * * *$ & 183 \\
\hline & \multirow{3}{*}{$\begin{array}{l}\text { System C } \\
\text { (RoGator) }\end{array}$} & LO & $195 * * *$ & $185 * * *$ & $116 * *$ & 166 \\
\hline & & RO & $132 * * *$ & $162 * * *$ & $128 * * *$ & 141 \\
\hline & & pooled & $164 * * *$ & $174 * * *$ & $122 * * *$ & 153 \\
\hline
\end{tabular}

[a] Systems A and C had a significantly larger RMSD than System B at each sensor location, at each speed, on each terrain.

[b] For each sensor or pooled sensors, boom height RMSD was significantly larger for System A or System B compared to System B: * p < $0.05, * * \mathrm{p}<0.01, * * * \mathrm{p}<0.001$

[c] Mean of averages at the three speeds were not tested for statistical significance

2012; Tahmasebi et al., 2013; Herbst et al., 2018; Miles, 2018). Unidentified automatic boom height systems have been compared in a lab setting (27-36 m, 89-120 ft) (Herbst et al., 2018) and in a field setting (33 m, $100 \mathrm{ft}$ ) (Miles, 2018), but this is the first reported comparison between identified, commercial automatic boom height systems.

By all metrics System B outperformed Systems A and C at each sensor location, at each speed, on each terrain (figs. 4-6; tables 2, 3, and S1). These differences were significant in all 108 comparisons between System B and System A and in 104 out of 108 comparisons between System B and System C. System B kept the boom height significantly closer to target as shown by RMSD, $\mathrm{f}_{10}$ and $\mathrm{f}_{<25}$ results (figs. 4-6), with significantly less variability, as shown by RMSD (fig. 4). This was also shown by the boom heights over two courses (fig. 2) and histograms of boom heights at the maximum common speed for each course (fig. 3). These demonstrate that System B drastically reduced extreme variations compared to Systems A and C.

The practical implication of System B's improved performance is that System B holds the boom closer to target with less variability. Though measuring spray dispersion and drift were outside of the scope of this work, less variability in boom height suggests that a sprayer will provide better dispersion consistency, reduce spray droplet drift, and reduce boom and crop damage. Figure 7 shows an idealized spray dispersion from a boom with the prescribed boom height of $50 \mathrm{~cm}$ for $110^{\circ}$ tips at $50 \mathrm{~cm}$ spacing (Forney et al., 2017). At the target height, each portion of the ground is covered by spray from two adjacent tips (fig. 7a). As the boom is lowered, this overlap does not occur at the outer tips, which could result in underapplication (fig. 7b). At a target height of $50 \mathrm{~cm}$ (20 in.), streaking occurs when the boom is lower than about $25 \mathrm{~cm}\left(10 \mathrm{in}\right.$.) at the outer sensor ( $\mathrm{f}_{<25}$, figs. $7 \mathrm{c}$ and $7 \mathrm{~d}$ ). When streaking occurs, some parts of the ground receive concentrated chemical and other parts receive no chemical. Streaking could lead to the administration of sublethal doses of herbicide, which could cause weeds to develop herbicide resistance (Neve and Powles, 2005; Busi and Powles, 2011; Tehranchian et al., 2017).

As the height of the boom increases, droplet drift increases (Holterman et al., 1997; Nuyttens et al., 2007; Baetens et al., 2009). For example, when boom height increases from 40 to

Table 3. Average boom height $f_{10}$ and $f_{<25}$ differences (\%) for System B relative to Systems $A$ and $C^{[a]}$

\begin{tabular}{|c|c|c|c|c|c|c|c|c|c|c|}
\hline \multirow[b]{3}{*}{ Course } & \multirow{3}{*}{$\begin{array}{c}\text { System } \\
\text { (Sprayer) }\end{array}$} & \multirow[b]{3}{*}{ Sensor } & \multicolumn{4}{|c|}{ Average $\mathrm{f}_{10}$ Difference $(\%)^{[\mathrm{b}]}$} & \multicolumn{4}{|c|}{ Average $\mathrm{f}_{<25}$ Difference $(\%)^{[\mathrm{b}]}$} \\
\hline & & & \multicolumn{3}{|c|}{ Speed $(\mathrm{km} / \mathrm{h})$} & \multirow[b]{2}{*}{ Avg. ${ }^{[c]}$} & \multicolumn{3}{|c|}{ Speed $(\mathrm{km} / \mathrm{h})$} & \multirow[b]{2}{*}{ Avg. ${ }^{[c]}$} \\
\hline & & & 13 & 19 & 26 & & 13 & 19 & 26 & \\
\hline \multirow{6}{*}{$\begin{array}{l}\text { Straightaway } \\
\text { (mild terrain) }\end{array}$} & \multirow{3}{*}{$\begin{array}{c}\text { System A } \\
\text { (R4045) }\end{array}$} & $\mathrm{LO}$ & $80 * * *$ & $88 * * *$ & $92 * *$ & 87 & $25 * * *$ & $32 * * *$ & $44 * * *$ & 34 \\
\hline & & $\mathrm{RO}$ & $56 * *$ & $68 * * *$ & $73 * * *$ & 66 & $18 * *$ & $28 * * *$ & $35 * * *$ & 27 \\
\hline & & pooled & $68 * * *$ & $78 * * *$ & $82 * * *$ & 76 & $22 * * *$ & $30 * * *$ & $39 * * *$ & 30 \\
\hline & \multirow{3}{*}{$\begin{array}{l}\text { System C } \\
\text { (RoGator) }\end{array}$} & $\mathrm{LO}$ & $25^{* *}$ & $24 * *$ & $29 *$ & 26 & $4 *$ & $9 * * *$ & $8 * *$ & 7 \\
\hline & & $\mathrm{RO}$ & $24 * *$ & $34 * * *$ & $43 * *$ & 34 & $3 * *$ & $6 * * *$ & $9 * *$ & 6 \\
\hline & & pooled & $25 * * *$ & $29 * * *$ & $36 * * *$ & 30 & $4 * * *$ & $8 * * *$ & $8 * * *$ & 7 \\
\hline \multirow{6}{*}{$\begin{array}{c}\text { Waterway } \\
\text { (medium } \\
\text { terrain) }\end{array}$} & \multirow{3}{*}{$\begin{array}{c}\text { System A } \\
\text { (R4045) }\end{array}$} & LO & $111 * *$ & $162 * * *$ & $93 * *$ & 122 & $50 * * *$ & $47 * * *$ & $76 * *$ & 58 \\
\hline & & $\mathrm{RO}$ & $75 * * *$ & $94 * *$ & $78 * *$ & 82 & $55 * * *$ & $48 * *$ & $35 * * *$ & 46 \\
\hline & & pooled & $93 * * *$ & $128 * * *$ & $85 * * *$ & 102 & $52 * * *$ & $48 * * *$ & $56 * * *$ & 52 \\
\hline & \multirow{3}{*}{$\begin{array}{l}\text { System C } \\
\text { (RoGator) }\end{array}$} & LO & $30 * *$ & $52 * * *$ & $49 * *$ & 44 & $15 * * *$ & $28 * *$ & $17 * *$ & 20 \\
\hline & & $\mathrm{RO}$ & $27 * *$ & $42 * *$ & $3^{\mathrm{NS}}$ & 24 & $9 * * *$ & $11^{\mathrm{NS}}$ & $25^{*}$ & 15 \\
\hline & & pooled & $29 * * *$ & $47 * * *$ & $26^{\mathrm{NS}}$ & 34 & $12 * * *$ & $20 * * *$ & $21 * * *$ & 18 \\
\hline & \multirow{2}{*}{$\begin{array}{c}\text { System } \\
\text { (Sprayer) }\end{array}$} & & \multicolumn{3}{|c|}{ Speed $(\mathrm{km} / \mathrm{h})$} & & \multicolumn{3}{|c|}{ Speed $(\mathrm{km} / \mathrm{h})$} & \\
\hline Course & & Sensor & 10 & 13 & 16 & Avg. ${ }^{[c]}$ & 10 & 13 & 16 & Avg. ${ }^{[c]}$ \\
\hline \multirow{6}{*}{$\begin{array}{c}\text { Terraces } \\
\text { (rough } \\
\text { terrain) }\end{array}$} & \multirow{3}{*}{$\begin{array}{c}\text { System A } \\
\text { (R4045) }\end{array}$} & $\mathrm{LO}$ & $88 * *$ & $114 * * *$ & $131 * *$ & 111 & $59 * *$ & $90 * * *$ & $120 * *$ & 90 \\
\hline & & $\mathrm{RO}$ & $59 * *$ & $121 * * *$ & $111 * *$ & 97 & $57 *$ & $93 * *$ & $122 * *$ & 91 \\
\hline & & pooled & $73 * * *$ & $118 * * *$ & $121 * * *$ & 104 & $58 * * *$ & $91 * * *$ & $121 * * *$ & 90 \\
\hline & \multirow{3}{*}{$\begin{array}{l}\text { System C } \\
\text { (RoGator) }\end{array}$} & $\mathrm{LO}$ & $67 * *$ & $102 *$ & $47^{\mathrm{NS}}$ & 72 & $41 * * *$ & $65 * *$ & $42 * *$ & 49 \\
\hline & & $\mathrm{RO}$ & $62 * *$ & $71 * * *$ & $39 *$ & 57 & $39 * *$ & $46 * *$ & $37 * *$ & 41 \\
\hline & & pooled & $64 * * *$ & $86 * * *$ & $43 * *$ & 64 & $40 * * *$ & $55 * * *$ & $39 * * *$ & 45 \\
\hline
\end{tabular}

[a] System $\mathrm{B}$ had significantly larger $\mathrm{f}_{10}$ and $\mathrm{f}_{<25}$ values at each sensor location, at each speed, on each terrain, except for four sensor/speed/terrain combinations. For each exception System B had a larger average $\mathrm{f}_{10}$ or $\mathrm{f}_{<25}$ difference but the difference was not statistically significant.

[b] For each sensor or pooled sensors, $\mathrm{f}_{10}$ or $\mathrm{f}_{<25}$ was significantly larger for System B compared to System A or System C: $* \mathrm{p}<0.05, * * \mathrm{p}<0.01, * * * \mathrm{p}$ $<0.001$, NS p $>0.05$.

[c] Mean of averages at the three speeds were not tested for statistical significance. 


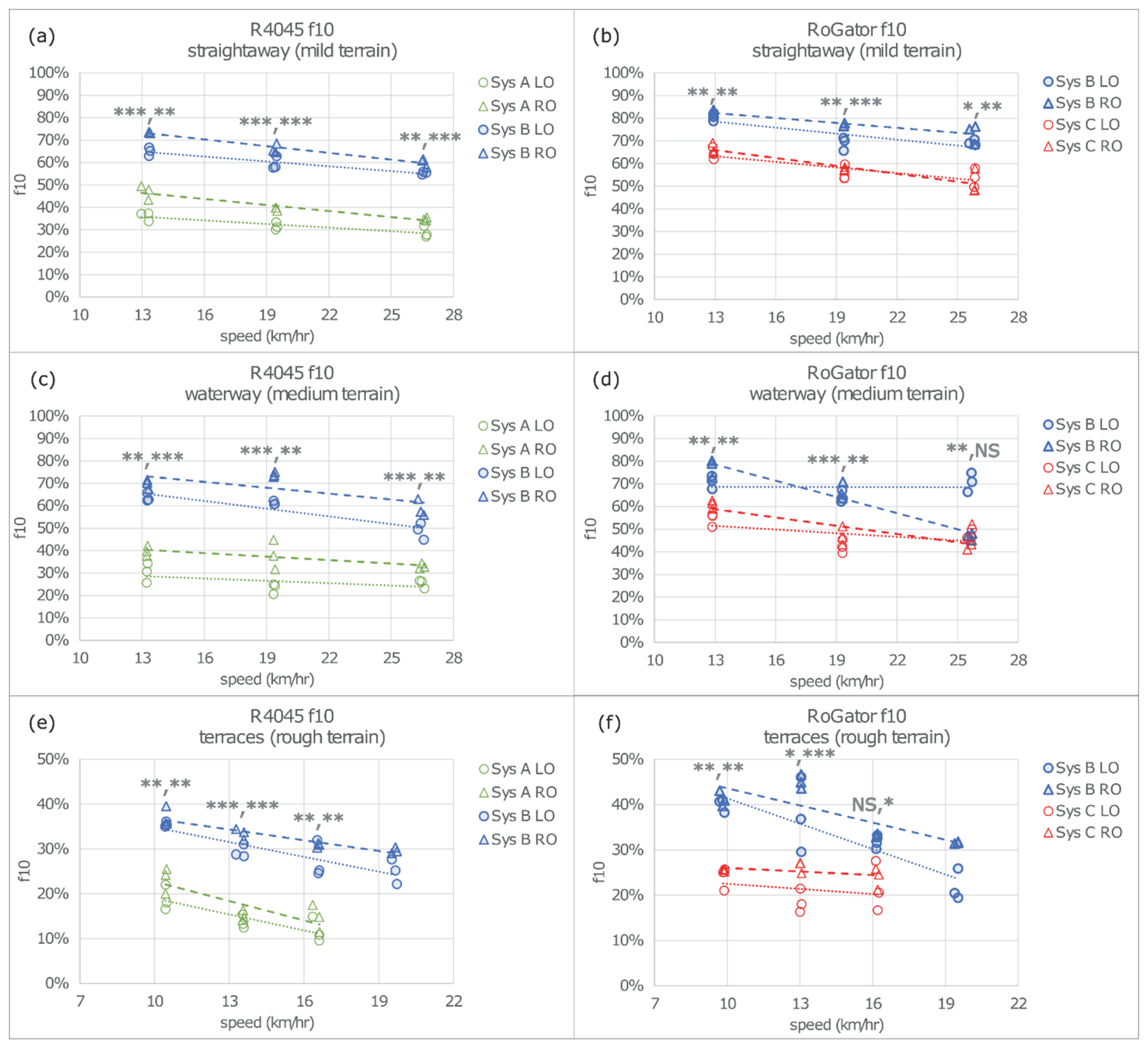

Figure 5. Boom height $f_{10}$ of left outside (LO) and right outside (RO) sensors. Panels (a), (c), and (e) are on the R4045; (b), (d), and (f) are on the RoGator; (a) and (b) are on the straightaway (mild terrain); (c) and (d) are on the waterway (medium terrain); and (e) and (f) are on the terraces (rough terrain). Significance is indicated for each speed by (left outside, right outside) where $* p<0.05, * * p<0.01, * * * p<0.001$, and NS $p>$ 0.05. System $B$ had a significantly larger $f_{10}$ than Systems $A$ and $C$ for each sensor location at each speed on each course with two exceptions: there was no significant difference between Systems B and C RO sensor on the waterway at $26 \mathrm{~km} / \mathrm{h}$ (panel d) and Systems B and C LO sensor on the terrace at $16 \mathrm{~km} / \mathrm{h}$ (panel f).

$80 \mathrm{~cm}$, the drift percentage triples (Nordby and Skuterud, 1975). At $26 \mathrm{~km} / \mathrm{h}$ on medium terrain, the fraction of points within $25 \mathrm{~cm}\left(\mathrm{f}_{<25}\right)$ was $56 \%$ and $21 \%$ higher for System B than Systems A and C, respectively. This means that Systems $\mathrm{A}$ and $\mathrm{C}$ could have streaking or drift issues $56 \%$ and $21 \%$ more frequently than System B.

\section{Performance Metric Comparison}

There is no industry standard metric for boom height performance. RMSD shows the variability in boom height from target for each system and this metric best differentiated the systems in this study. Similarly, the analogous measure "Standard Deviation" (of deviations from target) from Herbst et al. (2018) was the best metric to differentiate system performance. HHI has some limitations as a universal performance metric. First, it does not have any units which makes it difficult to interpret. For example, it is not intuitive to understand the meaning of System B's larger average HHI difference of 0.53 and 0.20 on the waterway at $26 \mathrm{~km} / \mathrm{h}$ compared to Systems A and C, respectively [Supplemental table S1 (Burgers et al., 2021b)]. Second, the assignment of the height ranges (bins) in the calculation [Supplemental equation 1 (Burgers et al., 2021b)] is subjective and the importance of the ranges could be dependent on the application, crop, chemical, or performance goal (Miles, 2018). The $\mathrm{f}_{10}$ and $\mathrm{f}_{<25}$ metrics are more intuitive because they are given as fractions or percentages but also are limited because the 10 and $25 \mathrm{~cm}$ limits are somewhat arbitrary. On a $36.6-\mathrm{m}(120-\mathrm{ft})$ width sprayer, with the sensor locations used in this study, $\mathrm{f}_{<25}$ has a practical implication because it approximates a height where streaking begins to occur, but if the boom width or sensor locations are much different, $\mathrm{f}_{<25}$ will also lose its practical implication. 


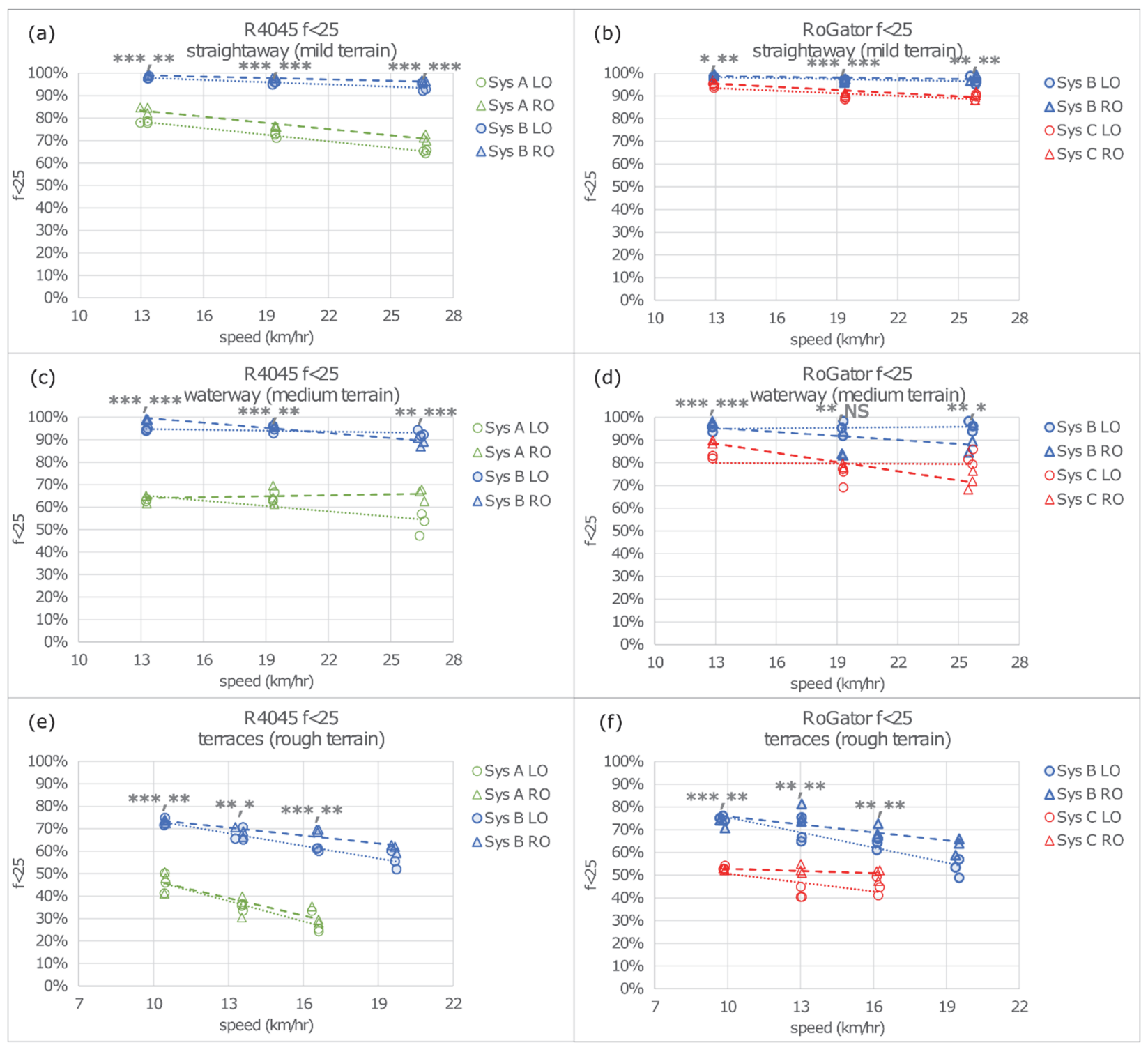

Figure 6. Boom height $\mathrm{f}_{<25}$ of left outside (LO) and right outside (RO) sensors. Panels (a), (c), and (e) are on the R4045; (b), (d), and (f) are on the RoGator; (a) and (b) are on the straightaway (mild terrain); (c) and (d) are on the waterway (medium terrain); and (e) and (f) are on the terraces (rough terrain). Significance is indicated for each speed by (left outside, right outside) where * $p<0.05, * * p<0.01, * * * p<0.001$, and NS $p>$ 0.05. System $B$ had a significantly larger $f_{<25}$ than Systems $A$ and $C$ for each sensor location at each speed on each course with one exception: there was no significant difference between Systems B and C RO sensor on the waterway at $19 \mathrm{~km} / \mathrm{h}$ (panel d).

\section{STUDY LIMITATIONS}

Considerable effort was made to make an objective comparison in this study, but every parameter could not be fully investigated or controlled. One limitation of this study was that there was no sensitivity analysis performed on adjusting the response sensitivity settings of each system, but for all systems, an effort was made to use good performance settings available to an operator. System A was operated in "Flat" mode on the straightaway and "Hilly" mode on the terraces because a pilot test showed the variability of each mode was smaller on its respective track. System B settings were chosen for each sprayer based on tuning results that an operator performs. System C sensitivity was chosen because it had the best qualitative performance (and fewer boom contacts with the ground) on pilot tests with sensitivities of 5, 8, and 10 .
Throughout the testing, autosteering and speed control were engaged to ensure repeatability of the track route and speed between test runs. The test run order was alternated to reduce any bias due to course changes that could occur from repeated test runs. The same portion of the track based on distance was used to evaluate data instead of a time interval of the data log which would result in comparisons over inconsistent portions of the track. The consistency of the track evaluation region is shown in the consistent chassis roll angle and speed profiles in figure 1. Figures $1 \mathrm{a}$ and $1 \mathrm{~b}$ show the consistency of 18 runs each $(3$ runs $\times 3$ speeds $\times 2$ systems). Figures $1 \mathrm{c}$ and $1 \mathrm{~d}$ show the consistency of 21 runs each $(3$ runs $\times$ 3 speeds $\times 2$ systems plus three System B runs at $19 \mathrm{~km} / \mathrm{h}$ ). Figures $1 \mathrm{e}, 1 \mathrm{f}, 1 \mathrm{~g}$, and $1 \mathrm{~h}$ show the consistency of six runs at each speed, except three runs at $19 \mathrm{~km} / \mathrm{h}$ on the terraces (figs. 1g and 1h) for System B and none for Systems A or C. 

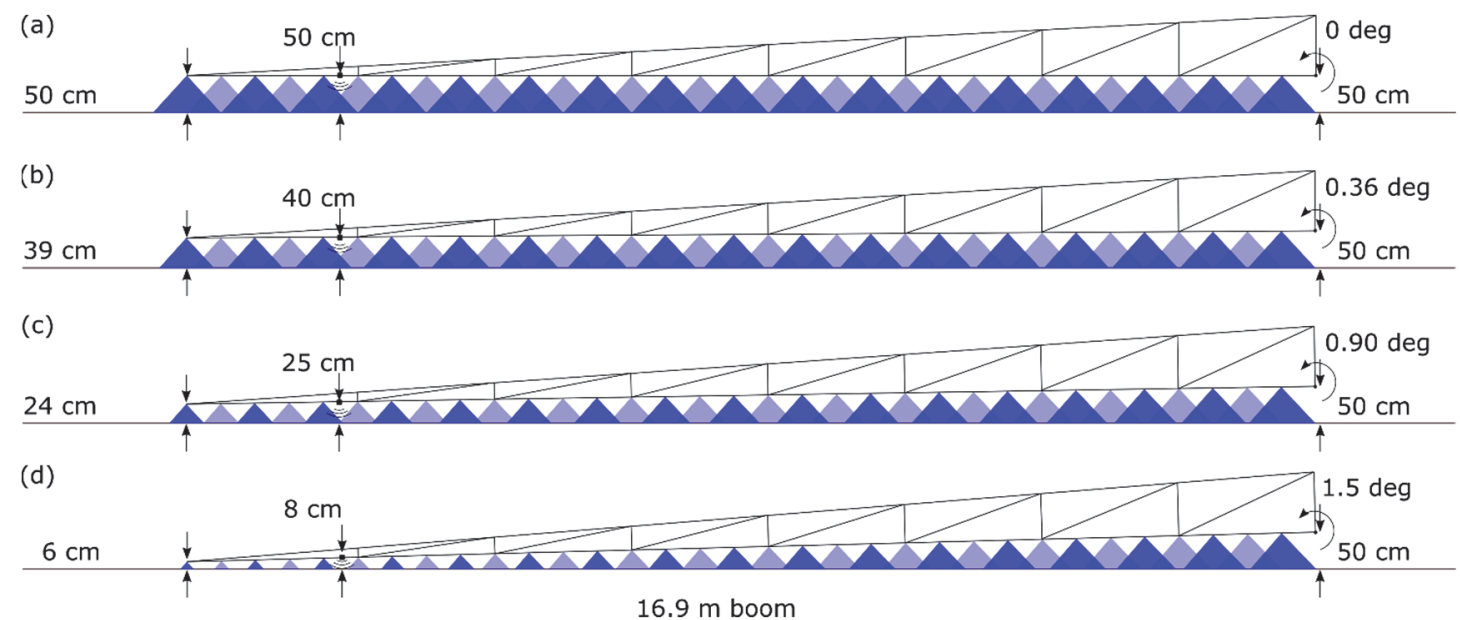

Figure 7. Idealized spray dispersion from $110^{\circ}$ tips at $50 \mathrm{~cm}$ spacing on a $16.9 \mathrm{~m}$ left boom (e.g., RoGator) with adjacent tips spraying alternating blue colors. (a) Level boom at $50 \mathrm{~cm}$ boom height, (b) boom tilted downward with outer sensor $10 \mathrm{~cm}$ (f $\left.\mathrm{f}_{10}\right)$ from target, (c) boom tilted downward with outer sensor $25 \mathrm{~cm}\left(f_{<25}\right)$ from target and (d) boom tilted downward $1.5^{\circ}$. When the boom is level (a), each portion of ground is covered by the output of two spray tips. When the boom is tilted downward at $f_{<25}(\mathrm{c})$, there is no overlap at the outer tips. As the boom tilts farther, streaking occurs at the outer tips.

The same height measurement sensors (from AutoBoom XRT) were used to take all height measurements to ensure all heights and performance metrics were based on a consistent measurement device. These AutoBoom XRT sensor measurements were used in the System B control system but were not used for the System A and C control systems because those used their own measurement sensors. Occasional obvious sensor inaccuracies were observed as large jumps in boom height over a short time (e.g., fig. 2b System C LO at $611 \mathrm{~m}$ and fig. 2d System B LO at $129 \mathrm{~m}$ ). These were included in all calculations because the number of inaccurate data points was minimal compared to the large number of accurate data points and thus would have a minimal effect on all output metrics. The minimum average number of data points calculated on a course was 542 data points for System A on the waterway at $29 \mathrm{~km} / \mathrm{h}$.

The discussion of the boom height results contextualized the practical implication of boom height variability. This discussion was theoretical because this study was limited to measuring boom heights, and the effect of automatic boom leveling on spray dispersion or spray drift was not measured.

This study included a range of speeds over a range of terrains. Despite this, another limitation of this study was that all tracks were over firm sod and there were no crops present. All three automatic boom height systems evaluated also have a mode that controls boom height to the top of the crop instead of the ground, but this mode was not used in any of the testing. A crop mode test would have additional challenges: any damage to the crop from the boom could change the course and crop height detection may differ depending on the type of crop. An additional limitation is that only three systems were used. Norac also has a $\mathrm{UC}^{\mathrm{TM}}$ system and Active Roll ${ }^{\mathrm{TM}}$ and Active Wing Roll $^{\mathrm{TM}}$ variations, but the three systems chosen for this study were available in North America at the time of testing.

\section{Conclusion}

This study was the first to report the performance of identified, commercial automatic boom height systems. Three leading North American automatic boom height systems were compared (John Deere BoomTrac Pro, Raven AutoBoom XRT, and Norac UC5 Passive Roll). Each system was evaluated with three test runs at three speeds over each of a mild, medium and rough terrain course. With four exceptions out of 216 comparisons, System B significantly outperformed Systems $\mathrm{A}$ and $\mathrm{C}$ for each metric, at each sensor location, at each speed, on each terrain. System B kept the boom height significantly closer to target and with significantly less variability. The results of this work demonstrate that the boom will occasionally be higher than $50 \mathrm{~cm}$ above target (figs. 2 and 3). Based on a typical target height of $50 \mathrm{~cm}$, additional research is warranted to measure spray drift with boom heights above $1 \mathrm{~m}$ (Byass and Lake, 1977; Holterman et al., 1997). Further research could also be performed to evaluate automatic boom height systems in different soil conditions, to determine if sensitivity settings could optimize performance under certain conditions, and to evaluate the effect of automatic boom leveling on spray dispersion.

\section{ACKNOWLEDGEMENTS}

We thank Alex Weidenbach and Gerry Breen for their technical assistance and Randy Clements and Tom Wenzel for their logistical support.

\section{CONFLICT OF INTEREST}

All authors are employees of Raven Industries. Raven Industries funded this study. Raven Industries has two submitted patents for AutoBoom XRT, but none of the authors are inventors on those patents. JDG and BJH own Raven stock.

\section{REFERENCES}

Baetens, K., Ho, Q. T., Nuyttens, D., De Schampheleire, M., Endalew, A. M., Hertog, M. L.,... Verboven, P. (2009). A validated 2-D diffusion-advection model for prediction of drift from ground boom sprayers. Atmos. Environ., 43(9), 1674-1682. https://doi.org/10.1016/j.atmosenv.2008.12.047 
Burgers, T. (2021). MATLAB scripts for "Comparison of three commercial automatic boom height control systems for agricultural sprayers.” St. Joseph, MI: ASABE. https:/doi.org/10.13031/13721722.v1

Burgers, T., \& Gaard, J. (2021). MATLAB data for "Comparison of three commercial automatic boom height systems for agricultural sprayers.” St. Joseph, MI: ASABE. https:/doi.org/10.13031/13721734.v1

Burgers, T., Gaard, J., \& Hyronimus, B. (2021a). Summary results for "Comparison of three commercial automatic boom height control systems for agricultural sprayers." St. Joseph, MI: ASABE. https:/doi.org/10.13031/13721716.v1

Burgers, T., Gaard, J., \& Hyronimus, B. (2021b). Supplemental information for "Comparison of three commercial automatic boom height control systems for agricultural sprayers." St. Joseph, MI: ASABE. https:/doi.org/10.13031/13721704.v1

Busi, R., \& Powles, S. B. (2011). Reduced sensitivity to paraquat evolves under selection with low glyphosate doses in Lolium rigidum. Agron. Sustainable Dev., 31(3), 525-531. https://doi.org/10.1007/s13593-011-0012-6

Butts, T. R., Luck, J. D., Fritz, B. K., Hoffmann, W. C., \& Kruger, G. R. (2019). Evaluation of spray pattern uniformity using three unique analyses as impacted by nozzle, pressure, and pulsewidth modulation duty cycle. Pest Manag. Sci., 75(7), 18751886. https://doi.org/10.1002/ps.5352

Byass, J. B., \& Lake, J. R. (1977). Spray drift from a tractorpowered field sprayer. Pesticide Sci., 8(2), 117-126. https://doi.org/10.1002/ps.2780080202

Carroll, J. (2017). The effects of sprayer speed and droplet size on herbicide burndown efficacy. MS thesis. Fayetteville: University of Arkansas, Agricultural and Extension Education Department.

Clijmans, L., Ramon, H., Sas, P., \& Swevers, J. (2000). Sprayer boom motion, part 2: Validation of the model and effect of boom vibration on spray liquid deposition. J. Agric. Eng. Res., 76(2), 121-128. https://doi.org/10.1006/jaer.2000.0531

Egan, J. F., Barlow, K. M., \& Mortensen, D. A. (2014). A metaanalysis on the effects of 2, 4-D and dicamba drift on soybean and cotton. Weed Sci., 62(1), 193-206. https://doi.org/10.1614/WS-D-13-00025.1

Everitt, J. D., \& Keeling, J. W. (2009). Cotton growth and yield response to simulated 2, 4-D and dicamba drift. Weed Technol., 23(4), 503-506. https://doi.org/10.1614/WT-08-061.1

Forney, S. H., Luck, J. D., Kocher, M. F., \& Pitla, S. K. (2017). Laboratory and full boom-based investigation of nozzle setup error effects on flow, pressure, and spray pattern distribution. Appl. Eng. Agric., 33(5), 641-653. https://doi.org/10.13031/aea.12043

Foster, H. C., Sperry, B. P., Reynolds, D. B., Kruger, G. R., \& Claussen, S. (2018). Reducing herbicide particle drift: Effect of hooded sprayer and spray quality. Weed Technol., 32(6), 714721. https://doi.org/10.1017/wet.2018.84

Griffin, J. L., Bauerle, M. J., Stephenson, D. O., Miller, D. K., \& Boudreaux, J. M. (2013). Soybean response to dicamba applied at vegetative and reproductive growth stages. Weed Technol., 27(4), 696-703. https://doi.org/10.1614/WT-D-13-00084.1

Griffith, J., Strelioff, B., \& Schnaider, J. (2012). The Hockley Index. ASABE Paper No. 121337379. St. Joseph, MI: ASABE. https://doi.org/10.13031/2013.41775

Herbst, A., Osteroth, H.-J., \& Stendel, H. (2018). A novel method for testing automatic systems for controlling the spray boom height. Biosyst. Eng., 174, 115-125. https://doi.org/10.1016/j.biosystemseng.2018.06.003

Holterman, H. J., van de Zande, J. C., Porskamp, H. A., \& Huijsmans, J. F. (1997). Modelling spray drift from boom sprayers. Comput. Electron. Agric., 19(1), 1-22. https://doi.org/10.1016/S0168-1699(97)00018-5
Langenakens, J. J., Clijmans, L., Ramon, H., \& De Baerdemaeker, J. (1999). The effects of vertical sprayer boom movements on the uniformity of spray distribution. J. Agric. Eng. Res., 74(3), 281-291. https://doi.org/10.1006/jaer.1999.0464

Langenakens, J. J., Ramon, H., \& De Baerdemaeker, J. (1995). A model for measuring the effect of tire pressure and driving speed on horizontal sprayer boom movements and spray pattern. Trans. ASAE, 38(1), 65-72. https://doi.org/10.13031/2013.27813

Lardoux, Y., Sinfort, C., EnfÃalt, P., \& Sevila, F. (2007). Test method for boom suspension influence on spray distribution, Part I: Experimental study of pesticide application under a moving boom. Biosyst. Eng., 96(1), 29-39. https://doi.org/10.1016/j.biosystemseng.2006.08.014

Meyer, C. J., Norsworthy, J. K., Kruger, G. R., \& Barber, T. (2016). Effects of nozzle selection and ground speed on efficacy of Liberty and Engenia applications and their implication on commercial field applications. Weed Technol., 30(2), 401-414. https://doi.org/10.1614/WT-D-15-00145.1

Miles, L. (2018). Developing general procedure to quantitatively analyze boom height control performance on self-propelled agricultural sprayers. MS thesis. Ames: Iowa State Univ.

Neve, P., \& Powles, S. (2005). High survival frequencies at low herbicide use rates in populations of Lolium rigidum result in rapid evolution of herbicide resistance. Heredity, 95(6), 485492. https://doi.org/10.1038/sj.hdy.6800751

Nordby, A., \& Skuterud, R. (1975). The effects of boom height, working pressure and wind speed on spray drift. Weed Res., 14(6), 385-395. https://doi.org/10.1111/j.13653180.1974.tb01080.x

Nuyttens, D., De Schampheleire, M., Baetens, K., \& Sonck, B. (2007). The influence of operator-controlled variables on spray drift from field crop sprayers. Trans. ASABE, 50(4), 1129-1140. https://doi.org/10.13031/2013.23622

Paraforos, D. S., Sharipov, G. M., \& Griepentrog, H. W. (2019). ISO 11783-compatible industrial sensor and control systems and related research: A review. Comput. Electron. Agric., 163, 104863. https://doi.org/10.1016/j.compag.2019.104863

Ramon, H., \& De Baerdemaeker, J. (1997). Spray boom motions and spray distribution: Part 1, derivation of a mathematical relation. J. Agric. Eng. Res., 66(1), 23-29. https://doi.org/10.1006/jaer.1996.0114

Scoll, J. P. (2019). Dicamba: A dispatch from the weed wars. Natural Resour. Environ., 33(4), 64.

Speelman, L., \& Jansen, J. W. (1974). The effect of spray-boom movement on the liquid distribution of field crop sprayers. $J$. Agric. Eng. Res., 19(2), 117-129. https://doi.org/10.1016/00218634(74)90027-4

Tahmasebi, M., Rahman, R. A., Mailah, M., \& Gohari, M. (2013). Active force control applied to spray boom structure. Appl. Mech. Materials, 315, 616-620. https://doi.org/10.4028/www.scientific.net/AMM.315.616

Tehranchian, P., Norsworthy, J. K., Powles, S., Bararpour, M. T., Bagavathiannan, M. V., Barber, T., \& Scott, R. C. (2017). Recurrent sublethal-dose selection for reduced susceptibility of Palmer amaranth (Amaranthus palmeri) to dicamba. Weed Sci., 65(2), 206-212. https://doi.org/10.1017/wsc.2016.27

Werle, R., Oliveira, M. C., Jhala, A. J., Proctor, C. A., Rees, J., \& Klein, R. (2018). Survey of Nebraska farmers' adoption of dicamba-resistant soybean technology and dicamba off-target movement. Weed Technol., 32(6), 754-761. https://doi.org/10.1017/wet.2018.62

Womac, A. R., Melnichenko, G., Steckel, L., Montgomery, G., Reeves, J., \& Hayes, R. M. (2017). Spray tip configurations with pulse-width modulation for glufosinate-ammonium deposits in Palmer amaranth (Amaranthus palmeri). Trans. ASABE, 60(4), 1123-1136. https://doi.org/10.13031/trans.12137 